\title{
Risk of exposure of a selected rural population in South Poland to allergenic mites. Part I: indoor acarofauna of one-family houses
}

\author{
Krzysztof Solarz ${ }^{1}$ (D) . Celina Pająk ${ }^{2}$
}

Received: 5 September 2018 / Accepted: 21 February 2019 / Published online: 28 February 2019 (c) The Author(s) 2019

\begin{abstract}
The aim of this study was to investigate the occurrence of mites in dust samples from houses in agricultural areas of South Poland, with particular reference to allergenic and parasitic species as a potential risk factor of diseases among people. A total of 250 dust samples from 50 single-family houses situated in Stryszawa and vicinity (Małopolskie province) were examined for the presence of domestic mites. Dust was taken from beds, floors in bedrooms, upholstery furniture, floors in family rooms and from floors in kitchens. Mites were found in $74.8 \%$ of samples collected. A total of 5340 mite specimens were isolated, including 2771 members of the family Pyroglyphidae (51.9\%). Dominants were Dermatophagoides pteronyssinus (36.4\% of all mites) and Gohieria fusca (25.1\%), followed by Chortoglyphus arcuatus (18.3\%) and D. farinae (15.1\%). Dermatophagoides pteronyssinus was also the most frequent species $(53.2 \%$ of the total count of samples examined), followed by G. fusca (42.4\%), D. farinae (37.2\%) and C. arcuatus (36.4\%). Lepidoglyphus destructor was found more frequently than Glycyphagus domesticus in the examined samples. Density of $D$. pteronyssinus was associated with beds, presence of pets, coal stoves used for heating, lower number of rooms, higher cooking frequency, higher washing frequency, working housewife, open kitchen, wooden floors in kitchens, lower cleaning frequency, type of upholstery furniture in living rooms (arm chairs), lower humidity and higher temperature.
\end{abstract}

Keywords Allergenic mites · House dust mites · Dermatophagoides spp. · Rural area · Poland

Krzysztof Solarz

solarzk@sum.edu.pl

1 Department of Parasitology, Faculty of Pharmacy with the Division of Laboratory Medicine in Sosnowiec, Medical University of Silesia in Katowice, Jednosci 8, 41-218 Sosnowiec, Poland

2 Department of Biochemistry and Molecular Biology, Faculty of Health Sciences, University of Bielsko-Biala, Willowa 2, 43-300 Bielsko-Biala, Poland 


\section{Introduction}

The most abundant mites in house dust are members of the family Pyroglyphidae (Acari: Sarcoptiformes, Astigmatina), in particular Dermatophagoides pteronyssinus, D. farinae and Euroglyphus maynei. These house dust mites are the major sources of indoor inhalant allergens facilitating both the sensitization of atopic subjects and asthmatic attacks in patients (Boquete et al. 2006; Colloff 2009; Thomas et al. 2010; Mastrorilli et al. 2016). Most often these mites are found in habitats intimately associated with man, such as beds, couches, sofas, other upholstered furniture, clothing and carpets (Colloff 2009; Aller 2010; Solarz 2010). But the house dust mites have been reported from a wide variety of other habitats associated with man and his environment, both indoor and outdoor (Neal et al. 2002; Solarz et al. 2007; Colloff 2009). Additional studies in different countries and regions of the world are also required to give a balanced view of indoor mite diversity. Most studies on house dust mites within dwellings have traditionally sampled beds, carpets and upholstered furniture as the three main types of indoor mite microhabitats (Colloff 2009). An understanding of the life cycle of house dust mites, their population age structure and seasonal dynamics, as well as environmental factors influencing mite populations, can be exploited in mite control (Harving et al. 1993; Hart 1998; Korsgaard 1998a, b; Solarz 2001b). For these reasons, additional studies in different countries and regions of the world are needed.

The aim of this investigation was to study (1) the occurrence, prevalence and species composition of the domestic mite fauna in house dust samples from beds, couches, sofas, upholstery furniture, carpets, wooden floors and linoleums in one-family houses situated in Stryszawa and vicinity (South Poland); (2) levels of house dust infestation with mites in particular sites of the examined places; (3) the main habitats of house dust mite occurrence and breeding in the examined houses; and (4) the influence of air temperature, humidity, and other environmental factors or housing conditions on the abundance and frequency of domestic mites, especially of the family Pyroglyphidae.

\section{Materials and methods}

The faunistic study was carried out from May 2011 to September 2012. A total of 250 dust samples from 50 single family houses situated in Stryszawa and vicinity (South Poland) were examined for a presence of domestic mites. In each house, dust was taken from five places: from beds (or other sleeping accommodations) and floors in bedrooms, from upholstery furniture and floors in family rooms, and from floors of kitchens. All samples were collected with portable vacuum cleaners, on a specially constructed dust trap (a sterile linen filter) attached to the end of the hose. A new filter was used for each sample, and each sample was kept separately. A surface area of $1 \mathrm{~m}^{2}$ at each sampling site was vacuumed for $1 \mathrm{~min}$. Next, the samples were weighed and analyzed for mites as described by Solarz (2001a) with some modifications. First of all, the samples were prepared by soaking in $75 \%$ ethanol for $4 \mathrm{~h}$, and then suspended in a saturated $\mathrm{NaCl}$ solution and a few drops of soap, and held for $24 \mathrm{~h}$ of floatation. After this time, supernatants were filtered through Whatman no. 388 filter paper. Sediments were again suspended in $\mathrm{NaCl}$ solution- the procedure was repeated at least $3 \times$. Filters with material retained were placed in Petri dishes and poured over with saturated $\mathrm{NaCl}$ solution. Next, the surfaces of liquid and filter papers were carefully examined for mites under a Olympus Europe Highlight 2100 binocular 
stereomicroscope, starting $24 \mathrm{~h}$ after pouring. All mites were mounted in Hoyer's medium on microscope slides. All mite specimens collected were examined using differential interference contrast (Nomarski DIC) (under a Zeiss Axioskope 2 plus light microscope) and phase contrast optics (under an Olympus $\mathrm{CH} 40$ light microscope). The identification of mites was made using descriptions of taxa and the following keys or publications: Fain et al. (1990), Baker (1999), Colloff (2009), Krantz and Walter (2009) and Solarz (2012).

When samples were taken, indoor ambient air temperature and relative humidity in each house were measured with digital humidity/temperature meters TES 1360 (TES Electrical Electronic Corporation) across the houses. In each home a thermohygrometer was always turned-on during the whole time of sampling/vacuuming of all five places examined and finally the average values were noted. Samples were taken between May 2011 and September 2012 at about noon each day of sampling. Most samples was taken in July, August and September, during months of peaks of mite density in dwellings in temperate climates.

Mite density was calculated as the number of specimens per $\mathrm{g}$ of dust. To standardize mite collection, the calculation of mite numbers of each taxon per $\mathrm{g}$ house dust was recommended by Platts-Mills et al. (1992) as the best method for determining exposure to mites and mite allergens. Information on various parameters which could influence mite numbers was obtained by questioning the residents and analyzed using Spearman's rank correlation test. These parameters were: type of place examined, type and age of building, presence or absence of pets, type of heating, number of rooms, family size (number of inhabitants), cooking and washing frequency (per week), housewife (unemployed or employed), type of sleeping accommodations and type of floors in bedrooms (carpeted or not), type of kitchen (open or closed), type of floors in kitchens, cooking facility, cleaning frequency, type of upholstery furniture, indoor relative humidity $(\% \mathrm{RH})$, indoor ambient air temperature $\left({ }^{\circ} \mathrm{C}\right)$, and weight of samples (in g).

The variables noted in the examined buildings were valuated as follows: type of place examined (kitchen floor $=1$, living room floor $=2$, bedroom floor $=3$, upholstery furniture $=4$; bed or other sleeping accommodation $=5$ ), type of building (brick house $=1$, wooden house $=2$ ), presence or absence of pets ( absent $=0,1$ animal $=1$, two animals $=2$, three and more $=3$ ), type of heating (central=1, coal stoves $=2$ ), housewife (unemployed $=0$, employed $=1$ ), type of sleeping accommodations $(\operatorname{arm}$-chair $=1, \operatorname{couch}=2$, settee $=3$, sofa $=4$, typical bed [with mattress] $=5$ ), type of floor in bedroom $(\mathrm{PVC}=1$, wooden floor $=2$, carpeted floor $=3)$, type of kitchen $($ closed $=1$, open $=2)$, type of floor in kitchen (tiles $=1$, linoleum $=2, \mathrm{PVC}=3$, panels $=4$, wooden floor $=5$ ), cooking facility (gas $=1$, combined gas and electric $=2$, electric $=3$, combined gas, electric and coal stoves $=4$, combined gas and coal stoves $=5$, only coal stoves $=6$ ), type of upholstery furniture (arm-chair full set $=1$, $\operatorname{couch}=2$, sofa $=3$, settee $=4$ ), type of the upholstery furniture covering $(\mathrm{smooth} / \mathrm{sky}=1$, smooth material [cloth texture] $=2$, plush $=3$ ).

The criterion variables analyzed were: number of mites per $\mathrm{g}$ dust, in relation to a particular species, total house dust mites (=Pyroglyphidae), total domestic mites (=Pyroglyphidae and other allergenic Astigmatina) and total mites (= all mite taxa collected). 


\section{Results}

\section{Composition of acarofauna}

The mean $( \pm S D)$ age of examined houses constituted 54.8 years $( \pm 25.2$; median 50.0 ; range 10-100 years). Mean number of inhabitants during the study was $3.5( \pm 1.71$; median 3 ; range 1-8 persons). The weight of samples ranged from 0.06 to $3.25 \mathrm{~g}$ (mean $\pm \mathrm{SD}$ $0.57 \pm 0.51$; median 0.39 ). Mean levels of relative humidity and temperature in the examined buildings during collection of dust samples were $60.1 \pm 6.2 \%$ and $23.8 \pm 1.8{ }^{\circ} \mathrm{C}$.

Mites were found in 187 of the 250 samples collected $(74.8 \%$ ) (Table 1). A total of 5,340 mite specimens were isolated, including 2,771 members of the family Pyroglyphidae (51.91\%). Dominant were the pyroglyphid D. pteronyssinus $(\mathrm{n}=1945,36.4 \%$ of all mites), the glycyphagid Gohieria fusca $(\mathrm{n}=1340,25.1 \%)$, the chortoglyphid Chortoglyphus arcuatus $(\mathrm{n}=978,18.3 \%)$ and the pyroglyphid $D$. farinae $(\mathrm{n}=804,15.1 \%)$. Moreover, within the Pyroglyphidae, 22 specimens of E. maynei $(0.42 \%)$ and 1 female of $H$. chelidonis were identified. Among other allergenic non-pyroglyphid mites there were the glycyphagids Lepidoglyphus destructor (1.39\%) and Glycyphagus privatus (1.35\%) and the acarid Tyrophagus putrescentiae (Table 1).

Table 1 Species list, dominance, abundance and frequency of mites found in the examined house dust samples from houses in Stryszawa and vicinity (Małopolskie province)

\begin{tabular}{|c|c|c|c|c|}
\hline \multirow[t]{2}{*}{ Mite taxa } & \multicolumn{2}{|c|}{ Dominance } & \multicolumn{2}{|c|}{ Frequency } \\
\hline & $\mathrm{N}$ & $\mathrm{D}(\%)$ & $\mathrm{n}$ & $\mathrm{F}(\%)$ \\
\hline Dermatophagoides pteronyssinus & 1945 & 36.42 & 133 & 53.2 \\
\hline Dermatophagoides farinae & 804 & 15.06 & 93 & 37.2 \\
\hline Euroglyphus maynei & 22 & 0.41 & 5 & 2.0 \\
\hline Hirstia chelidonis & 1 & 0.02 & 1 & 0.4 \\
\hline Gohieria fusca & 1340 & 25.09 & 106 & 42.4 \\
\hline Glycyphagus domesticus & 7 & 0.13 & 5 & 2.0 \\
\hline Glycyphagus privatus & 72 & 1.35 & 4 & 1.6 \\
\hline Lepidoglyphus destructor & 74 & 1.39 & 16 & 6.4 \\
\hline Chortoglyphus arcuatus & 978 & 18.31 & 91 & 36.4 \\
\hline Tyrophagus putrescentiae & 2 & 0.04 & 2 & 0.8 \\
\hline Tyrophagus longior & 1 & 0.02 & 1 & 0.4 \\
\hline Thyreophagus entomophagus & 1 & 0.02 & 1 & 0.4 \\
\hline Caloglyphus berlesei & 1 & 0.02 & 1 & 0.4 \\
\hline Xenoryctes sp. & 3 & 0.06 & 3 & 1.2 \\
\hline Cheyletus sp. & 55 & 1.03 & 28 & 11.2 \\
\hline Tarsonemidae & 4 & 0.07 & 2 & 0.8 \\
\hline Pygmephoridae & 2 & 0.04 & 2 & 0.8 \\
\hline Tetranychidae & 4 & 0.07 & 2 & 0.8 \\
\hline Oribatida (sensu lato) & 8 & 0.15 & 5 & 2.0 \\
\hline Mesostigmata & 16 & 0.30 & 16 & 6.4 \\
\hline Acari (total) & 5340 & 100 & 187 & 74.8 \\
\hline
\end{tabular}

$N$ number of mite specimens, $n$ number of positive samples, $D(\%)$ percentage of total count of mites collected, $F(\%)$ percentage of total number of samples examined $(n=250)$ 
Dermatophagoides pteronyssinus was also the most frequent species and was found in 133 samples (53.2\% of the total count of samples examined), followed by G. fusca $(42.4 \%)$, D. farinae (37.2\%) and C. arcuatus (36.4\%) (Table 2). The difference in frequency between $D$. pteronyssinus and $D$. farinae was statistically significant $\left(\chi^{2}=5.17, \mathrm{p}=0.023\right)$. The first species was also significantly more frequent than $C$. arcuatus $\left(36.4 \% ; \chi^{2}=5.85, \mathrm{p}=0.016\right)$, whereas the difference in frequency between $G$. fusca and $C$. arcuatus was not significant $\left(\chi^{2}=0.76, \mathrm{p}=0.38\right)$, as was the difference in frequency between $G$. fusca and $D$. farinae $\left(\chi^{2}=0.52, \mathrm{p}=0.47\right)$. Lepidoglyphus destructor was found more frequently than Glycyphagus domesticus in the examined house-dust samples but this difference was not significant $\left(\chi^{2}=2.08, \mathrm{p}=0.15\right)$.

\section{Diversity of mite taxa in particular places}

In bedrooms, both in beds and on floors, occurred the same four mite species, D. pteronyssinus, D. farinae, G. fusca and C. arcuatus (Table 2). Beds were dominated by G. fusca (39.1\%) and D. pteronyssinus (37.6\%), but bedroom floors by D. pteronyssinus $(49.3 \%)$ and $C$. arcuatus $(19.95 \%)$. The latter species was significantly less frequent in beds than on floors in bedrooms and living rooms $\left(\chi^{2}=14.59, p=0.0001\right)$ or than on floors of

Table 2 Dominance, frequency and mean $( \pm S D)$ abundance (number of mites per $g$ dust) of the four most numerous mite species found in dust sampled from beds, bedroom floors, upholstery furniture of living rooms, living-room floors and kitchen floors of houses in Stryszawa and vicinity (Małopolskie province)

\begin{tabular}{|c|c|c|c|c|c|c|}
\hline \multirow[t]{2}{*}{ Sample sources } & \multirow[t]{2}{*}{ Mites } & \multicolumn{2}{|c|}{ Dominance } & \multicolumn{2}{|c|}{ Frequency } & \multirow[t]{2}{*}{ Abundance $($ mean \pm SD) } \\
\hline & & $\mathrm{N}$ & $\mathrm{D}(\%)$ & $\mathrm{n}$ & $\mathrm{F}(\%)$ & \\
\hline \multirow[t]{4}{*}{ Bed dust } & Dermatophagoides pteronyssinus & 563 & 37.61 & 36 & 72 & $20.64 \pm 51.7$ \\
\hline & D. farinae & 221 & 14.77 & 24 & 48 & $10.94 \pm 28.65$ \\
\hline & Gohieria fusca & 585 & 39.07 & 22 & 44 & $11.36 \pm 31.98$ \\
\hline & Chortoglyphus arcuatus & 128 & 8.55 & 5 & 10 & $7.90 \pm 17.06$ \\
\hline \multirow[t]{4}{*}{ Bedroom floor } & D. pteronyssinus & 475 & 49.63 & 26 & 52 & $10.48 \pm 17.61$ \\
\hline & D. farinae & 105 & 10.98 & 17 & 34 & $9.05 \pm 17.85$ \\
\hline & G. fusca & 186 & 19.44 & 22 & 44 & $16.62 \pm 53.71$ \\
\hline & C. arcuatus & 191 & 19.95 & 16 & 32 & $10.23 \pm 25.43$ \\
\hline \multirow{4}{*}{$\begin{array}{l}\text { Upholstery fur- } \\
\text { niture of living } \\
\text { room }\end{array}$} & D. pteronyssinus & 413 & 41.01 & 23 & 46 & $17.44 \pm 33.64$ \\
\hline & D. farinae & 153 & 15.19 & 16 & 32 & $5.83 \pm 13.80$ \\
\hline & G. fusca & 204 & 20.26 & 23 & 46 & $12.42 \pm 42.59$ \\
\hline & C. arcuatus & 237 & 23.54 & 24 & 48 & $13.99 \pm 39.17$ \\
\hline \multirow[t]{4}{*}{ Living-room floor } & D. pteronyssinus & 232 & 32.36 & 26 & 52 & $18.63 \pm 31.54$ \\
\hline & D. farinae & 161 & 22.45 & 17 & 34 & $6.49 \pm 14.61$ \\
\hline & G. fusca & 181 & 25.24 & 20 & 40 & $24.05 \pm 122.96$ \\
\hline & C. arcuatus & 143 & 19.95 & 16 & 32 & $18.50 \pm 44.89$ \\
\hline \multirow[t]{4}{*}{ Kitchen floor } & D. pteronyssinus & 242 & 31.84 & 19 & 38 & $30.57 \pm 62.14$ \\
\hline & D. farinae & 135 & 17.76 & 19 & 38 & $15.45 \pm 29.70$ \\
\hline & G. fusca & 215 & 28.29 & 18 & 36 & $48.86 \pm 200.29$ \\
\hline & C. arcuatus & 168 & 22.11 & 17 & 34 & $25.39 \pm 65.26$ \\
\hline
\end{tabular}

$N$ number of mite specimens, $n$ number of positive samples, $D(\%)$ percentage of total count of mites collected, $F(\%)$ percentage of the total number of samples positive for mites $(\mathrm{n}=50)$ 
kitchens $\left(\chi^{2}=16.78, p<0.00001\right)$. Moreover, it was significantly more frequent in samples from upholstery furniture in living rooms than in beds or other sleeping accommodations $\left(\chi^{2}=35.07, p<0.00001\right)$. Dermatophagoides pteronyssinus and D. farinae were collected more frequently from bed dust samples than from floors in bedrooms or living rooms (Table 2) and both differences were significant $\left(\chi^{2}=8.49, p=0.004\right.$ and $\chi^{2}=4.05$, $p=0.044$, respectively).

The same four species were also the most abundant ones in the remaining indoor places examined (Table 2). All these places were dominated by D. pteronyssinus. Its dominance was highest on bedroom floors, then on upholstery furniture, in beds, on living room floors, and its dominance was lowest on kitchen floors (Table 2). The dominance of $D$. farinae was highest in samples from floors of living rooms and from kitchens. Chortoglyphus arcuatus occurred most numerously on upholstery furniture, whereas G. fusca was most numerous in beds and on kitchen floors (Table 2). Differences in frequency are highest for $D$. pteronyssinus, between beds (72\%) and kitchen floors (38\%), and for C. arcuatus, between upholstery furniture $(48 \%)$ and beds $(10 \%)$; both differences were significant $\left(\chi^{2}=23.35\right.$ and 35.07, respectively, both $p \leq 0.00001)$. Gohieria fusca was more frequent in samples from upholstery furniture in living rooms and less frequent in samples from kitchen floors but the difference is not significant $\left(\chi^{2}=2.07, p=0.15\right)$. Dermatophagoides pteronyssinus was significantly more frequent than $D$. farinae in beds $\left(\chi^{2}=12.0, p=0.0005\right)$, in dust from bedroom and living room floors $\left(\chi^{2}=6.61, p=0.01\right)$ and in dust from upholstery furniture of living rooms $\left(\chi^{2}=4.12, p=0.042\right)$.

\section{Densities of mites}

Densities of mites per $\mathrm{g}$ of dust are presented in Table 3. Gohieria fusca was the most abundant mite species in the examined samples with (mean \pm SD) $22.7 \pm 110.4$ specimens per $g$ of dust, followed by D. pteronyssinus $(19.55 \pm 42.52)$ and C. arcuatus $(15.2 \pm 41.95)$. Dermatophagoides farinae, the second most medically important pyroglyphid species, was much less abundant, with $9.55 \pm 22.12$ specimens per g of dust. Generally, D. pteronyssinus

Table 3 Mean $( \pm \mathrm{SD})$, median and maximum number of mites per $g$ of dust in samples from houses situated in Stryszawa and vicinity (Małopolskie province)

\begin{tabular}{lcccc}
\hline Mites & Mean \pm SD & Median & Maximum & $\begin{array}{r}\text { Variability } \\
\text { coefficient }\end{array}$ \\
\hline Dermatophagoides pteronyssinus & $19.55 \pm 42.52$ & 3.60 & 342.40 & 217.43 \\
Dermatophagoides farinae & $9.55 \pm 22.12$ & 0.00 & 152.90 & 231.51 \\
Euroglyphus manyei & $0.32 \pm 2.38$ & 0.00 & 26.70 & 747.32 \\
Gohieria fusca & $22.66 \pm 110.40$ & 0.00 & 1154.50 & 487.21 \\
Glycyphagus privatus & $0.54 \pm 7.54$ & 0.00 & 118.60 & 1385.21 \\
Lepidoglyphus destructor & $0.51 \pm 4.66$ & 0.00 & 71.60 & 919.35 \\
Chortoglyphus arcuatus & $15.20 \pm 41.95$ & 0.00 & 312.50 & 275.94 \\
Cheyletus sp. & $0.63 \pm 2.82$ & 0.00 & 25.00 & 446.92 \\
House dust mites (Pyroglyphidae) & $29.89 \pm 52.45$ & 8.64 & 362.50 & 175.45 \\
Domestic mites (Pyroglyphidae +other & $43.06 \pm 155.85$ & 2.70 & 1418.1 & 361.88 \\
$\quad$ domestic Astigmatina) & & & & \\
Total mites & $73.80 \pm 163.40$ & 26.45 & 1418.1 & 221.41 \\
\hline
\end{tabular}


was also the most abundant species per $\mathrm{g}$ of dust. It was significantly more abundant in all types of places examined (Table 2).

The mean number of house dust mites per $g$ of dust in the examined houses constituted 29.9, and it was much lower than mean numbers of domestic mites (43.1) and total mites (73.8) per $g$ of dust. This implies that the other non-pyroglyphid mites are an important part of domestic acarofauna in the examined agricultural areas of South Poland.

\section{Environmental factors influencing density and prevalence of mites}

Table 4 shows the effects of temperature, relative humidity and other environmental factors on the densities of mites per $\mathrm{g}$ of dust in the examined houses. The results of Spearman's rank correlation test between some abiotic and biotic indoor environmental factors (housing conditions) and the mite prevalence and density in the examined dwellings suggests associations between the total mite density (per g of dust) and the following both abiotic or biotic factors: lower weight of sample, lower age of building, presence of pets, higher number of rooms, higher number of inhabitants (family size), working house wife, open kitchen, wooden floor in kitchen, type of cooking (coal stoves), lower cleaning frequency, type of upholstery furniture in living rooms (arm chairs), lower relative humidity and higher temperature (Table 4). Significant positive correlations were also found between density of domestic mites and: lower weight of sample, presence of pets, higher number of rooms, higher number of inhabitants (family size), working house wife, couches as type of sleeping, open kitchen, wooden floor in kitchen, type of cooking (coal stoves), type of upholstery furniture in living rooms (arm chairs), lower relative humidity and higher temperature. Density of D. pteronyssinus was associated with beds, presence of pets, coal stoves used for heating, fewer rooms, higher cooking frequency, higher washing frequency, working housewife, open kitchen, wooden floors in kitchens, lower cleaning frequency, type of upholstery furniture in living rooms (arm chairs), lower humidity and higher temperature. Density of $D$. farinae was influenced by coal stoves used for heating, higher cooking frequency, working housewife, carpeted floors in bedrooms, open kitchen, wooden floors in kitchens, lower cleaning frequency, type of upholstery furniture in living rooms (arm chairs), lower humidity and higher temperature. Other correlations were not significant.

Presence and abundance of E. maynei was influenced by higher number of rooms, couches, carpeted bedroom floors, coal stoves used for cooking and settee in living-rooms. In general, high densities of pyroglyphid mites (house dust mites) were associated with beds, lower age of buildings, presence of pets, coal stoves used for heating, higher cooking and washing frequency, working housewife, open kitchens, wooden floors in kitchens, lower cleaning frequency, armchairs in living rooms, type of the upholstery furniture covering (plush), lower humidity and higher temperature.

Abundance of $G$. fusca was associated with presence of pets, higher number of rooms and inhabitants, couches, open kitchens, and coal stoves used for cooking, whereas abundance of $C$. arcuatus was associated with presence of pets, higher number of rooms and inhabitants, employed house-wife, couches, open kitchens, wooden kitchen floors, and coal stoves used for cooking. Other correlations were negative or not significant. 


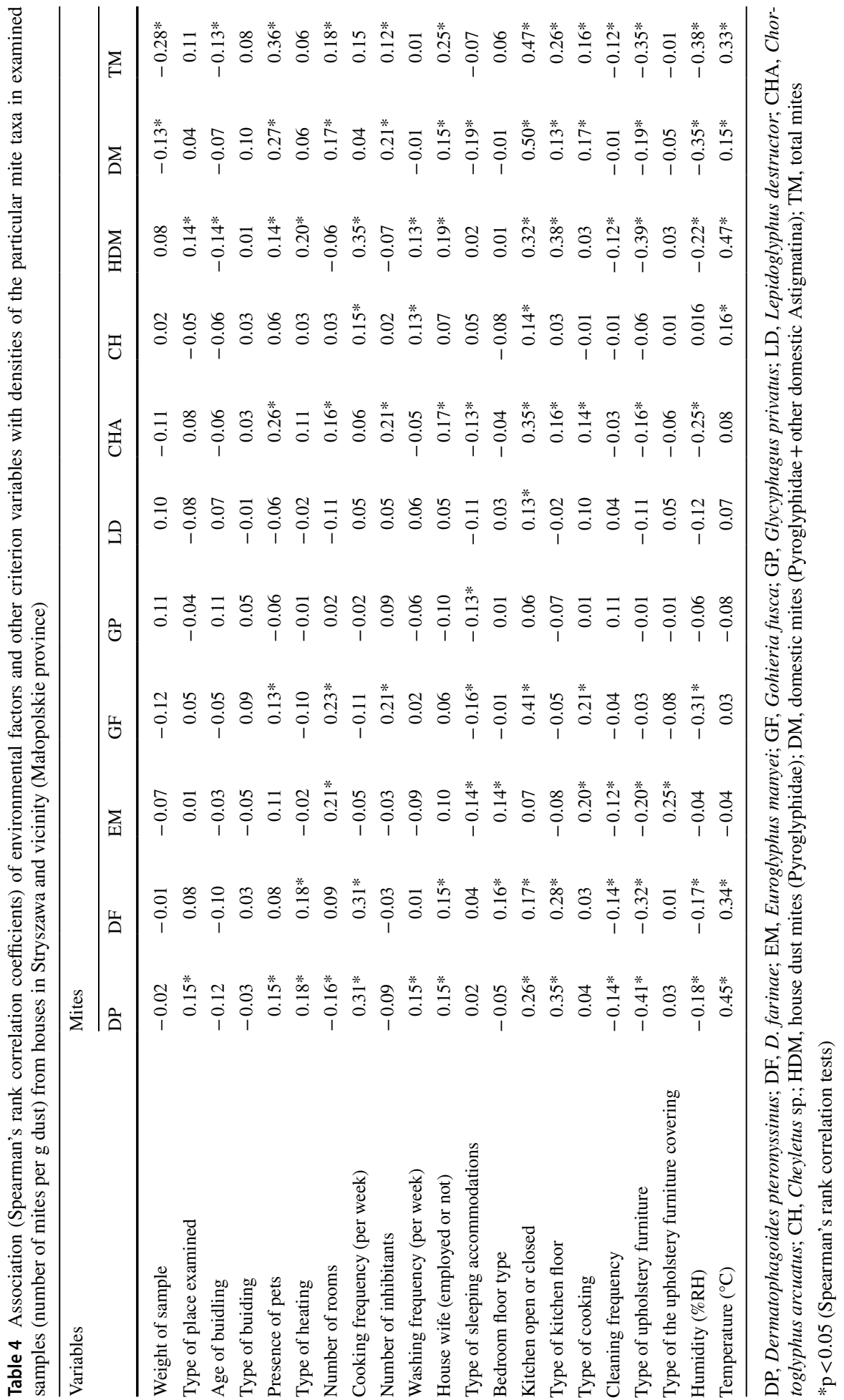




\section{Discussion}

Ratios of numbers of particular pyroglyphid dust mite species, especially between D. pteronyssinus and D. farinae, are different in separate regions of the world (Fain et al. 1990; Colloff 2009). Decisive factors influencing their occurrence and abundance are mainly relative humidity and temperature of both outdoor and indoor air. It is commonly known that the optimal temperature is higher $\left(25-30{ }^{\circ} \mathrm{C}\right)$ and optimal humidity lower $(50-75 \%$ $\mathrm{RH}$ ) for $D$. farinae than for $D$. pteronyssinus. The former species appear to survive better in dryer habitats than the latter, whereas lower temperature $\left(15-20^{\circ} \mathrm{C}\right)$ and higher humidity (75-80\% RH) favor D. pteronyssinus in mixed laboratory cultures (Dusbábek 1975; de Boer 1990; Arlian et al. 1998a, 1999; Solarz 2001b). Within the wide zone of temperate climate, D. pteronyssinus is the most common and dominant species in more damp areas, at the seaside or in lowlands, which have a more humid climate. Dermatophagoides farinae, on the other hand, is more common and abundant in areas with a dry continental climate (intercontinental and alpine regions) (Dusbábek 1975; de Boer 1990; Horak et al. 1996; Solarz 2001a, b, 2010). Therefore, mean values of relative humidity in the examined dwellings were slightly below a critical equilibrium humidity (CEH) for pyroglyphid house dust mites (especially for D. pteronyssinus and E. maynei) (Arlian et al. 1998a, b; Colloff 1991a, b, 2009), but they are distinctly higher than 45\% RH (the lowest threshold of indoor humidity for mite survival in dwellings) (Hart 1998; Korsgaard 1998a, b). As results of other surveys in Poland indicated, D. pteronyssinus was found as the dominant species in Bydgoszcz, Warsaw, Cracow, Łódź, Poznań and vicinity, Bielsko-Biała and Wodzisław, whereas D. farinae was dominant in Gdańsk and Gdynia, in West Pomerania, and in most of the Upper Silesian cities (Chmielewski 1995; Horak et al. 1996; Racewicz 2001; Solarz 2001a, 2012; Kosik-Bogacka et al. 2012). Summarizing, the domination of D. pteronyssinus in one-family houses appears to be characteristic for many agricultural or subagricultural localities in Poland (Solarz 2010). This tendency may also indicate that dwellings at these localities in Poland become more favorable for mites. The indoor air ambient humidity, which varies with the degree of ventilation of the dwellings, depends on the building construction (van Bronswijk and Schober 1991); therefore, energy-saving house insulation tends to increase indoor humidity and may lead to higher house dust mite densities (especially D. pteronyssinus) (Korsgaard 1998a). On the other hand, relative humidity was negatively correlated with the number of mites in the examined houses.

A wide range of abiotic environmental indoor factors have been analyzed for their influence on pyroglyphid mite populations in the hope that limiting factors may be exploited in control (Korsgaard and Iversen 1991; van der Hoeven et al. 1992; Harving et al. 1993; Hart 1998; Korsgaard 1998a, b; Solarz 2001b; Kasprzyk et al. 2014). In many studies, positive correlations were found between mite densities or allergen levels and relative (or absolute) air humidity of the dwelling (Korsgaard 1983a, 1998a, b; Hart and Whitehead 1990; Harving et al. 1993; Hart 1998; Kasprzyk et al. 2014). Hart (1998) published the following environmental factors positively influencing mite levels: humidity, type of heating, type of mattress (springs), type of bedding (without impermeable covers), age of mattress, carpets, soft furnishings, soft toys, age of house, frequency of cleaning, number of inhabitants, presence of smoking persons and pets. Results obtained by Kasprzyk et al. (2014) showed that occurrence and abundance of dust mites in urban areas of Upper Silesia are mainly influenced by humidity, age and type of building (one-family houses, old houses), type of sleeping accommodation (typical beds), type of floor (carpeted) and furniture (upholstered), type of wall (wallpapers), type of kitchen (open), higher cleaning 
and washing frequency and signs of moulds. It was also suggested that differences in the prevalence of mites between dwellings are a reflection of associations between the environmental requirements of mites or their biological characteristics (especially in relation to air humidity), and degree of indoor dampness, largely influenced by household activities, family size, dwelling space, cooking or washing frequency, and some other factors (Korsgaard and Iversen 1991; van der Hoeven et al. 1992; Solarz 2001b; Kasprzyk et al. 2014). These suggestions also correspond with the results actually obtained, except for humidity, and for number of rooms (house or flat size), which was considered as the dry factor in Japan (Sakaki and Suto 1995). Moreover, the age of a building was sometimes classified as the 'dry' factor (in the case of flats in urban areas), whereas in the case of single-family houses of a subagricultural settlement it could be classified as the 'humid' factor (Korsgaard and Iversen 1991; Hart 1998; Solarz 2001b; Kasprzyk et al. 2014). It was also suggested that at the present time, the only way to guarantee lower mite allergen levels in modern homes in the 'western world' is to remove the carpets and to encase the mattress (or other sleeping accommodation) and bedding (Simpson et al. 2001). Certain studies, however, showed weak or no correlation between these environmental factors and mite density (e.g., Ree et al. 1997).

Summarizing, the differences in the geographic distribution of particular species of both pyroglyphid house dust mites and domestic non-pyroglyphid mites, as well as the mite population densities both within and between dwellings or localities, are attributed to variation in biotic and abiotic factors of the indoor environment or in ecological requirements of the various mite species. During studies performed in South Poland (Solarz 2001a, b, 2010) it was found that mite populations on floors are more dependent on environmental factors (as the type of building, type of heating, relative humidity or temperature) than mites from the other places examined. Moreover, some sampling methods (sweepings, car vacuum cleaners) are more effective for collecting non-pyroglyphid domestic mites than for pyroglyphids. Generally, the older buildings and stoves are more favorable for the occurrence of both $D$. pteronyssinus and the domestic non-pyroglyphids, whereas new buildings, with central heating systems, favor the higher abundance of $D$. farinae.

Funding Funding was provided by Medical University of Silesia in Katowice (Grant no. KNW-1-137/N/8/I).

Open Access This article is distributed under the terms of the Creative Commons Attribution 4.0 International License (http://creativecommons.org/licenses/by/4.0/), which permits unrestricted use, distribution, and reproduction in any medium, provided you give appropriate credit to the original author(s) and the source, provide a link to the Creative Commons license, and indicate if changes were made.

\section{References}

Aller A (2010) A study of the areas and frequency of house dust mites Dermatophagiodes in Illinois Homes. ESSAI 7(1):6-9. http://dc.cod.edu/essai/vol7/iss1/8

Arlian LG, Confer PD, Rapp CM, Vyszenski-Moher DAL, Chang JSC (1998a) Population dynamics of the house dust mites Dermatophagoides farinae, D. pteronyssinus, and Euroglyphus maynei (Acari: Pyroglyphidae) at specific relative humidities. J Med Entomol 35:46-53.

Arlian LG, Neal JS, Bacon SW (1998b) Survival, fecundity and development of Dermatophagoides farinae (Acari: Pyroglyphidae) at fluctuating relative humidity. J Med Entomol 35:962-966.

Arlian LG, Neal JS, Vyszenski-Moher DAL (1999) Reducing relative humidity to control the house dust mite Dermatophagoides farinae. J Allergy Clin Immunol 104:852-856.

Baker AS (1999) Mites and ticks of domesic animals. An identification guide and information source. The Stationery Office, London. (ISBN 0-11-310049-3) 
Boquete M, Iraola V, Fernández-Caldas E, Arenas Villaroel L, Carballada FJ, González de la Cuesta C, López-Rico MR, Núñez Orjales R, Parra A, Soto-Mera MT, Varela S, Vidal C (2006) House dust mite species and allergen levels in Galicia, Spain: a cross-sectional, multicenter, comparative study. J Invest Allergol Clin Immunol 16(3):169-176.

Chmielewski W (1995) Mites (Acarina) In house dust of a basemat flat. In: Proceedings of the symposium on advances of acarology in Poland, Drukarnia ISK, Siedlce, pp 205-209.

Colloff MJ (1991a) Population studies on the house-dust mite, Euroglyphus maynei (Cooreman, 1950) (Pyroglyphidae). In: Schuster RH, Murphy PW (eds) The Acari. Reproduction, development and lifehistory strategies. Chapman and Hall, London, pp 497-505

Colloff MJ (1991b) A review of biology and allergeniciti of house-dust mite Euroglyphus maynei (Acari: Pyroglyphidae). Exp Appl Acarol 11:177-198

Colloff MJ (2009) Dust mites. Springer, CSIRO Publishing, Collingwood. (ISBN 978-90-481-2223-3)

de Boer R (1990) Effect of heat treatments on the house-dust mites Dermatophagoides pteronyssinus and $D$. farinae (Acari: Pyroglyphidae) in a mattress-like polyurethane foam block. Short Communication. Exp Appl Acarol 9:131-136.

Dusbábek F (1975) Population structure and dynamics of house dust mite Dermatophagoides farinae (Acarina:Pyroglyphidae) in Czechoslovakia. Folia Parasitol (Praha) 22:219-231.

Fain A, Guerin B, Hart BJ (1990) Mites and Allergic Disease. Allerbio, Varennes en Argonne. ( ISBN 90-71868-12-5)

Hart BJ (1998) Life cycle and reproduction of house-dust mites: environmental factors influencing mite populations. Allergy 53(Suppl. 48):13-17.

Hart BJ, Whitehead L (1990) Ecology of house dust mites in Oxfordshire. Clin Exp Allergy 20:203-209.

Harving H, Korsgaard J, Dahl R (1993) House-dust mites and associated environmental conditions in Danish homes. Allergy 48:106-109.

Horak B, Dutkiewicz J, Solarz K (1996) Microflora and acarofauna of bed dust from homes in Upper Silesia, Poland. Ann Allergy Asthma Immunol 76:41-50.

Kasprzyk M, Wilk I, Solarz K, Asman M, Sadowski T (2014) Influence of abiotic and biotic indoor environment factors on the allergenic and parasitic mite numbers in urban dwellings on the territory of Silesian Province In: Buczek A, Błaszak Cz (eds.) Arthropods. Impact on human and animal health. Koliber, Lublin, pp 333-348.

Korsgaard J (1983a) House-dust mites and absolute indoor humidity. Allergy 38:85-92.

Korsgaard J (1998a) Epidemiology of house-dust mites. Allergy 53(Suppl48):36-40.

Korsgaard J (1998b) House-dust mites and asthma. A review on house-dust mites as a domestic risk factor for mite asthma. Allergy 53(Supp148):77-83.

Korsgaard J, Iversen M (1991) Epidemiology of house dust mite allergy. Allergy 46(Suppl11):14-18.

Kosik-Bogacka DI, Kalisińska E, Henszel Ł, Kuźna-Grygiel W (2012) Seasonal dynamics of house dust mites in dust samples collected from sleeping places in North-Western Poland. Zoonoses Public Health. 59:8-15. https://doi.org/10.1111/j.1863-2378.2011.01409.x

Krantz GW, Walter DE (2009) A manual of acarology. Third edition. Texas Tech University Press, Lubbock. (ISBN 978-0-89672-620-8)

Mastrorilli C, Posa D, Cipriani F, Caffarelli C (2016) Asthma and allergic rhinitis in childhood: what's new. Pediatr Allergy Immunol 27:795-803. https://doi.org/10.1111/pai.12681

Neal JS, Arlian LG, Morgan MS (2002) Relationship among house-dust mites, Der 1, Fel d 1, and Can f 1 on clothing and automobile seats with respect to densities in houses. Ann Allergy Asthma Immunol $88: 410-415$.

Platts-Mills TAE, Wayne RT, Aalberse RC, Vervloet D, Chapman MD (1992) Dust mite allergens and asthma: report of Second International Workshop. J Allergy Clin Immunol 89:1046-1060.

Racewicz M (2001) House dust mites (Acari: Pyroglyphidae) in the cities of Gdańsk and Gdynia (Northern Poland). Ann Agric Environ Med 8:33-38.

Ree HI, Jeon SH, Lee IY, Hong CS, Lee DK (1997) Fauna and geographical distribution of house dust mites in Korea. Korean J Parasitol 35:9-17.

Sakaki I, Suto C (1995) Cluster analysis of domestic mites and housing conditions in wooden houses in Nagoya, Japan. Jap J San Zool 46:41-48.

Simpson A, Woodcock A, Custovic A (2001) Housing characteristics and mite allergen levels: to humidity and beyond. Clin Exp Allergy 3:803-805.

Solarz K (2001a) Risk of exposure to house dust pyroglyphid mites in Poland. Ann Agric Environ Med $8: 11-24$.

Solarz K (2001b) Pyroglyphidae (Acari: Astigmata) in Poland. Distribution, biology, population ecology and epidemiology. Acta Zool Cracov 44:435-528. 
Solarz K (2010) Temporal changes in the composition of house-dust-mite fauna in Poland. Acta Zool Cracov 53:39-64. https://doi.org/10.3409/azc.53b_1-2.39-64

Solarz K (2012) House dust mites and storage mites (Acari: Oribatida: Astigmatina). Identification keys. Institute of Systematics and Evolution of Animals Polish Academy of Sciences, Cracow. (ISBN 978-83-61358-48-0)

Solarz K, Seńczuk L, Maniurka H, Cichecka E, Peszke M (2007) Comparisons of the allergenic mite prevalence in dwellings and certain outdoor environments of the Upper Silesia (Southwest Poland). Int J Hyg Environ Health 210:715-724. https://doi.org/10.1016/j.ijheh.2006.11.007

Thomas WR, Hales BJ, Smith WA (2010) House dust mite allergens in asthma and allergy. Trends Mol Med 16(7):321-328. https://doi.org/10.1016/j.molmed.2010.04.008

van Bronswijk JEMH, Schober G (1991) Management of mite development in the home. In: Schuster R, Murphy PW (eds) The Acari. Reproduction, development and life-history strategies. Chapman and Hall, London, p 507-516.

van der Hoeven WAD, de Boer R, Bruin J (1992) The colonisation of new houses by house dust mites (Acari:Pyroglyphidae). Exp Appl Acarol 16:75-84.

Publisher's Note Springer Nature remains neutral with regard to jurisdictional claims in published maps and institutional affiliations. 